\title{
Promoting Military Cultural Awareness in an Off-post Community of Behavioral Health and Social Support Service Providers
}

\author{
Christi Duette Luby
}

\begin{abstract}
Due to U.S. military Base Realignment and Closure (BRAC) efforts and ongoing Overseas Contingency Operations, the number of military servicemembers and veterans seeking civilian-based services has increased. As the military presence grows in previously underrepresented areas, the need for culturally competent providers will also increase both on and off military installations. The purpose of this article is to promote military cultural awareness, while suggesting ways to enhance existing community behavioral health and social support services. It builds on a review of the extant literature and findings from a community assessment to introduce civilian providers to some specific issues affecting servicemembers and their families. A framework describes ways to increase military cultural competence and build community capacity to enhance civilian-based services. In addition, two appendices list some common military terminology and multiple training resources available through military organizations and websites.
\end{abstract}

Keywords: Military cultural competence, community capacity building, resources

According to the Department of Defense (DoD), since 2001 almost 2 million military personnel have deployed in support of Operation Enduring Freedom (OEF) and Operation Iraqi Freedom (OIF) (IOM, 2010). In addition, due to US military Base Realignment and Closure (BRAC) efforts, servicemembers and their families are relocating throughout the United States (DoD, 2005). These sustained military activities have increased the number of servicemembers, veterans, and their families seeking behavioral health and social support resources in civilian communities. The DoD believes the civilian sector will answer this call to duty and help meet this demand (US Medicine Institute (USMI), 2005).

The purpose of this paper is to promote awareness of the support necessary to improve the health of servicemembers and their families and identify resources available to providers to help meet those needs. The military represents a unique cultural group with its own language, behaviors, and beliefs (Reger et al., 2008). Issues faced by returning troops and their families may be unfamiliar to civilian providers, which may present challenges. How civilian providers respond to this increased need for services will determine their ability to offer ethical, culturally competent care (Reger, Etherage, Reger, \& Gahm, 2008).

According to Defense Centers of Excellence (DCoE) (2009), to serve military communities better, qualified resource providers should be sensitive to and willing to learn about the military culture. Gaining cross-cultural competence is an ongoing process that requires the application of professional practice standards to this unique population

Christi Duette Luby is a doctoral candidate in the Interdisciplinary Health Sciences Ph.D. Program at the College of Health Sciences/School of Nursing, University of Texas at El Paso. The views expressed in this document are those of the author(s) and do not reflect the official policy of William Beaumont Army Medical Center, the Department of the Army, or the United States Government.

Copyright (C 2012 Advances in Social Work Vol. 13 No. 1 (Spring 2012), 67-82 
(NASW, 2006). As one model suggests, providers must continuously integrate new information gathered through cultural awareness, knowledge and sensitivity to achieve cultural competence (Papadopoulos, Tilki, \& Taylor, 1998).

\section{METHOD}

This call to action originated from ideas generated during direct practice and involvement with military installations, as well as results from an assessment of a community affected by returning troops and BRAC. A convenience sample of 184 civilian-based resource providers received an online survey to assess their services available to military personnel, veterans, and their families. The assessment established baseline data for an ongoing evaluation of this community's capacity to provide behavioral health and related support services and to determine what civilian-based services need to better support this diverse group. For example, $78 \%$ of respondents stated they would like to receive more knowledge on military culture, organizational structure, and terminology, which resulted in the creation of a resource directory (Luby, 2010).

In response to this community's needs and others like it, this manuscript promotes awareness about specific issues affecting the military and gathers various resources for civilian practitioners to fill any knowledge gaps that may exist. Building on a review of the extant research literature and practice methods used by civilians engaged in military partnerships, this manuscript develops a framework that delineates ways to increase military cultural competence and build community capacity to enhance civilian-based services (see Figure 1).

This model reinforces many of the 2007 Standards for Cultural Competence in Social Work Practice, and encourages an ongoing process of cultural awareness, adaptation of skills, active involvement, and providing peer-support. Next, this review identifies specific cultural issues relevant to the military population and discusses implications for practice. Lastly, a table summarizes some common military stressors and two appendices introduce a brief military lexicon and examples of resources available to improve the care of servicemembers and their families.

\section{Conduct a Self-inventory}

To increase cultural competence, first the civilian-based service provider needs to conduct a self-inventory (Hall, 2008). This includes using self-awareness and honesty to evaluate his or her position on military issues, so that political opinions and personal values do not affect the care, services, or social support provided to special populations (Hall, 2008; NASW, 2006; Slone \& Friedman, 2008). This pre-assessment will help ensure professionals remain impartial and empathetic even when worldviews differ. 
Figure 1: Methods to Increase Military Cultural Competence

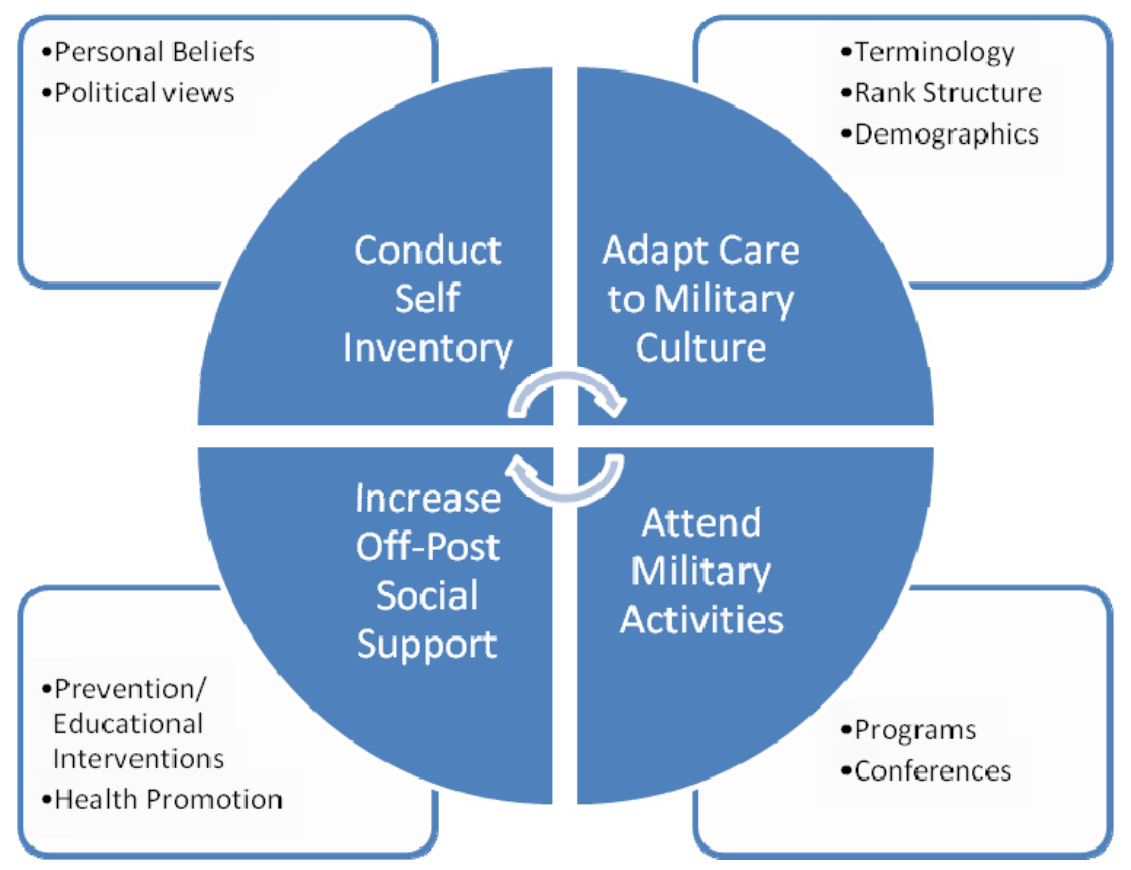

\section{Adapt Care to Military Culture}

\section{Mission and Values}

When working with diverse groups, providers may need to adapt their services and care to be consistent with the client's culture, whatever that culture may be (NASW, 2006). Engaging in military cultural competence requires both an awareness of the client's behaviors and values, as well as a willingness to develop a multicultural perspective as providers (Hall, 2008). Each military branch has developed its own primary mission, lexicon, and set of core values. These commonalities serve to develop cultural identity and facilitate communication and cohesion among its members (Abbe, Gulick, \& Herman, 2007; DCoE, 2009). As professionals learn and develop crosscultural skills, the delivery of services becomes more population specific, and therefore, more effective (Abbe, et al., 2007; NASW, 2006).

Many cultural minorities express greater comfort in receiving treatment from healthcare professionals of the same or similar backgrounds (Chassman \& Cave, 2011). In addition, some studies suggest that military members and their families respond better to help from providers that are either military affiliated or when providers attempt to understand them. For example, combat soldiers, who feel comfortable and supported by their community, heal faster and better because they are in a trusted place (Garcia, 2009). This suggests that if the civilian provider or a family member has served in the military, it 
may create a stronger provider-client connection if the servicemember is aware of this common bond.

When providers acquire a basic knowledge of military values, the ability to offer culture-specific care improves. This in turn will build a stronger therapeutic alliance and lead to better clinical care. All servicemembers are trained using concepts of honor, mission first, and belief in sacrificing oneself for others and the greater good (Buck, 1981; Hall, 2008). Words such as honor, integrity, courage, and strength are at the heart of the military culture and affect every aspect of the cultural identity. These words build morale--esprit de corps--within the unit and often influence how, when, and whether or not a servicemember will seek help (SAMHSA, 2006). In practice, sensitivity to these values establishes a critical link from the civilian-based service provider to the military client.

\section{Organizational Structure and Rank Hierarchy}

It is advantageous for practitioners to have a basic understanding of the US military organizational structure, as well as rank hierarchy (e.g., Officers, Enlisted) and titles, which vary with each Service Branch (i.e., Army, Air Force, Navy, Marine Corps, and Coast Guard) (DCoE, 2009). Therefore, providers may wish to acquire cultural-specific knowledge to the military branches they serve. Providers that understand the differences between the classifications (e.g., active duty, inactive duty, reserve, National Guard, and veteran) will appreciate how this status may influence the stressors to which servicemembers and their families may be exposed. For example, this status determines when, how often, and for how long a servicemember will deploy.

\section{Demographics}

Another way to augment an understanding of military culture is to examine general demographics of the population (DCoE, 2009). Servicemembers' current characteristics (age, gender, marital status, race/ethnicity, rank, and occupational area) may affect their military experience and level of stressors (DoD, 2010; Rand, 2007). Having cultural sensitivity includes knowing the military member's career or occupational specialty, which helps identify the potential occupational hazards or factors that may influence his or her experiences, and therefore, behavior.

\section{Cultural-specific Adaptation of Care}

Developing cross-cultural knowledge and skills to effectively meet the needs of military client groups will enhance civilian-based care models. For example, professionals without prior experience with military personnel will become more familiar with general military terminology, as well as deployment related expressions. Being able to converse with military and civilian treatment teams is a vital part of psychological assessments and command consultations (Reger, et al., 2008). Therefore, it is also beneficial for civilian staff to be qualified to assess post-traumatic, combat stress, depression, deployment, and reintegration issues in military members and their families (Cozza, 2011; Franklin, 2009; USMI, 2005). 
Combat-related treatment requires a multidisciplinary team, culturally sensitive to the diverse political, socioeconomic, and environmental factors affecting military populations (Hall, 2008). This interdisciplinary practice experience offers civilian providers an opportunity to practice intercultural competence and exhibit cross-cultural leadership skills (Abbe, et al., 2007; NASW, 2006). One study suggested that when general physicians had knowledge of military culture and the impact of war on combat veterans, this resulted in earlier diagnosis and successful psychotherapeutic treatment outcomes (Lee, Gabriel, \& Bale, 2005).

Due to stigma and other related issues, barriers to seek and receive care may exist for servicemembers and their families (SAMHSA, 2006). Some soldiers have expressed concerns that seeking behavioral healthcare will harm their career or opportunity to promote (Hall, 2008; Ruzek, et al., 2004; SAMHSA, 2006). In addition, military rank determines the pay grade, which may affect the availability of resources. Providers need strategies to decrease these barriers, and be prepared to address any confidentiality concerns the servicemember may have.

Civilian providers help make decisions before and after combat about fitness for duty and mental health status. This involves privacy issues for the solider, as well as assuring military commanders that the soldier is prepared to meet mission readiness (Kennedy \& Moore, 2008). Therefore, an understanding of military medical care, principles, practice, and policies is very important when treating this population. For example, specific diagnoses can prompt a review by a military Medical Evaluation Board. Certain codes assigned for diagnoses or reimbursement of services may affect a servicemember's ability to perform certain duties, maintain certain military occupational specialties and security clearances, which in turn will affect his/her ability to deploy (US Army, 2011). Guidance on filing claims is available for both civilian and military providers to address these issues through the DoD healthcare benefits program, TRICARE.

\section{Cultural-specific Adaptation of Care for Military Families}

Culturally competent care also includes appreciating and addressing the issues and challenges that affect military families. The ability to effectively interact, understand and communicate with servicemembers and their families improves the quality of care (DCoE, 2009). Military families are similar to civilian families in many ways; just some of their challenges differ. Civilian professional interested in including this group in their client base need to understand these unique challenges.

Everyone in the family makes personal sacrifices for the mission, in support of their servicemember's call to duty. Some military issues and stressors are common and affect most military personnel and their families (see Table 1). There are other stressors experienced by some family members, which require special attention and understanding. For example, those who help care for returning wounded, ill, and injured (WII) soldiers have additional challenges (WTC, 2011). Whether servicemembers are active-duty or veterans, civilian providers can help by ensuring continuity of care, which creates smoother transitions for the entire family. 
Table 1: $\quad$ Common Stressors Affecting Military Families

\begin{tabular}{|c|c|}
\hline $\begin{array}{l}\text { Top Three Concerns for Deployed } \\
\text { Service Member: } \\
\text { (Rabb, 2010) }\end{array}$ & $\begin{array}{l}\text { 1) Exposure to Combat } \\
\text { 2) Home-front Concerns } \\
\text { 3) Peer/Leaders Relationship }\end{array}$ \\
\hline $\begin{array}{l}\text { Military Service Member Stressors: } \\
\text { (Rabb, 2010) }\end{array}$ & $\begin{array}{l}\text { 1) High Risk Occupation; 2) Mobility; 3) Authoritative Work } \\
\text { Environment; 4) Effects on Families; 5) High degree of living } \\
\text { with uncertainty; 6) Impact of Separation; 7) Absence of } \\
\text { Community Support; 8) Loss of Income; 8) Minority Status } \\
\text { (w/in civilian pop); 9) Sense of isolation or not being } \\
\text { understood }\end{array}$ \\
\hline Behavioral expectations: & $\begin{array}{l}\text { Military members (and their families) are expected to conform } \\
\text { to professional and personal behavior, both on and off-duty. }\end{array}$ \\
\hline Deployment: & $\begin{array}{l}\text { Service member is called to duty (without his/her family) } \\
\text { somewhere other than the permanent duty station (ex. } \\
\text { humanitarian effort, support of a conflict.) } \\
\text { Time Varies by: Service Branch, Career Field, Mission }\end{array}$ \\
\hline $\begin{array}{l}\text { Permanent Change of Station: } \\
\text { (PCS) }\end{array}$ & $\begin{array}{l}\text { Active duty service members and their families are required to } \\
\text { move to different duty stations (approx. every 2-4 years) to } \\
\text { meet mission's needs, increase leadership opportunities and } \\
\text { career development. This is a stressful time for military families } \\
\text { (change schools; jobs; separate from family/support systems; } \\
\text { new area) }\end{array}$ \\
\hline Risk of injury or death: & Concern for a loved one's safety \\
\hline $\begin{array}{l}\text { Temporary Duty: } \\
\text { (TDY) }\end{array}$ & $\begin{array}{l}\text { Service member travel assignment away from duty stations } \\
\text { (approx. few days to few months-less than yr). (Ex. trainings, } \\
\text { conferences/meetings, temporary fill in) }\end{array}$ \\
\hline
\end{tabular}

Each member of the family handles military stressors differently; therefore, it may be beneficial to provide military sensitive, support services for each age group (Slone \& Friedman, 2008). This previously understudied area has recently received greater attention. A growing body of literature now focuses on age-specific issues and the effects of deployments and reintegration on military spouses and children. Additionally, regional online training covers a variety of military subjects to assist military and civilian-based practice providers. These free programs deliver professional education to enhance familiarity and build community capacity.

Providers helping families of deployed servicemembers may want to learn more about Family Readiness Groups (FRG). These groups activate as a part of the reardetachment, which includes those in the unit that stay at the home base during deployments (Operation READY, 2010). The FRG meets regularly to provide social support for the unit's military families and offer assistance to those with special needs while the servicemember deploys. 


\section{Attend Military Activities}

Another way to learn about the military culture is to attend military activities, including programs and military health conferences. For example, Army Posts often open their gates to the local community by sponsoring special events and inviting the public. Social interaction and community outreach events held on military installations provide a unique opportunity for civilian providers to see the priority population in surroundings where the group works and lives. In addition, resource providers that go to where the target community gathers will have a better understanding of the issues that affect their cultural identity and environment (Minkler, 1997).

There are also online activities available that address current military care issues. For example, the military's Defense Centers of Excellence for Psychological Health and Traumatic Brain Injury (DCoE) provides monthly web-based seminars on relevant topics affecting military members and their families. There are numerous opportunities to serve military servicemembers, veterans, and families both on and off military installations. In fact, the current presidential administration advertises a website to aid local communities and providers in finding ways to get involved (CNCS, 2010). When providers participate in these efforts to advocate for and empower others, the overall community capacity increases (Minkler, 1997; NASW, 2006).

\section{Increase Civilian Organizations’ Involvement and Provider Social Support}

Both military and civilian professionals can help facilitate civilian social support. These community capacity-building efforts may include networking with other military and civilian providers to champion for prevention and educational interventions for health promotion within the civilian community. To increase acceptance and sustainability of these public health initiatives, it is recommended that the target participants and community members be invited to be part of the development process (Minkler, 1997). If these providers work together to share knowledge and create a directory of the local and national resources available, this will improve referral networks and overall service delivery (NASW, 2006).

As for the provider's own self-care and social support, he or she should be aware that compassion fatigue and secondary traumatic stress are very real phenomena. It is important to realize and respect that some military member's experiences will differ from that of the average citizen. When working with traumatized servicemembers, symptoms of post-traumatic stress and combat stress may be present. The stories they share with providers may contain more violent or graphic information than the traumatic experiences of the average civilian population (Bride \& Figley, 2009). The experiences described may involve life or death situations, such as watching someone be harmed or killed, or the soldier may have had to kill someone.

Without proper training, those trying to help veterans may be injured psychologically due to secondary traumatic stress affects (Bride \& Figley, 2009). By listening to military stories, helpers become susceptible to vicarious traumatization from these horrific experiences (Figley, 1995). Therefore, healthcare professionals may benefit from forming 
a peer-to-peer support group to encourage other providers, or by attending professional continuing education that cover these specific trauma topics to develop coping skills.

\section{DISCUSSION}

The purpose of this paper is to promote awareness of the issues that affect military servicemembers and their families, to build the civilian community capacity to better serve this population, and to identify resources available to providers to help meet those needs. Military organizations do not expect civilian practitioners to completely change their mode of practice; but it seems providers who serve, treat, and care for servicemembers and their families should be sensitive to this unique culture and gain competence to provide optimal care.

This article develops a framework that depicts an ongoing process requiring time and commitment on the part of the provider. It promotes awareness of basic knowledge of policies, structure, and values to build a stronger alliance and promotes a responsive and comprehensive model of care. It addresses barriers to care, improving access to services and engaging family members, educators, and health providers in the unique needs of this population to help establish this comprehensive care model.

The military culture is unique in its core values, organizational structure, and terminology. Though made up of multiple diverse cultures, the US military cultural identity enhances uniformity amongst its members and conformity to the rules, policies and procedures that guide the overall mission. This article offers civilian-based services exposure to these distinct qualities, and promotes an awareness of the need to consider these issues during practice.

It is understood that civilian providers are busy and probably lack the necessary time to engage in every suggestion outlined in the model. Therefore, to save time for those interested in gaining familiarity with the military culture, this article provides an introduction and assembles information gathered from the research literature and used in the practice. If providers would like more information, numerous journals focus on a variety of military specific topics such as principles and practice, research, psychology, and medical ethics. In addition, multiple television dramas and movies have addressed a range of military issues to increase familiarity with this population; as well as, a military channel that reports current military news. When behavioral health and social support resource providers serving this community learn more about their issues, it will advance their level of understanding and improve their ability to help.

\section{IMPLICATIONS FOR PRACTICE}

Military installations and Veteran Centers are preparing for the influx of personnel and their families. Surrounding local communities affected by BRAC and returning veterans need to prepare as well. An assessment of the community would focus these efforts, provide a more complete picture of the community's healthcare and social support systems, and help to identify strengths, needs, and priorities. One of the ways to bridge the gap between military and civilian sectors is through empowerment and advocacy initiatives (CNCS, 2010). In addition, civilian-based providers engaged in 
strategic partnerships with military installations and the veterans' administration will find many funding opportunities available to organizations and universities interested in working with military families.

The National Association of Social Workers (2006) has policy statements and a Code of Ethics that urge social workers to be culturally competent. Universities that offer social work and licensed professional counselor programs will need a broad approach that reaches beyond the populations they usually serve. Developing course curriculum specific to the issues affecting active-duty military and veteran populations will prepare future providers and current providers through continuing education. In addition, courses that address compassion fatigue and secondary trauma stress that include evidence-based practice to increase coping skills and build resiliency may reduce the future risks of providers suffering from work related burnout.

Primary and secondary public schools who teach military children might look for collaborative approaches within the state school systems to make military transitions less difficult. For example, parents may deploy for twelve months at a time, which is longer than an academic school year. In addition, military families move approximately every three years. When educational systems and teachers are more aware of the issues, they can become actively involved in addressing these challenges. If they help and prepare families to adjust and avoid unnecessary distress, this focus will enhance military children's overall academic success.

\section{CONCLUSIONS}

The U.S. military Base Realignment and Closure (BRAC) efforts and ongoing Overseas Contingency Operations have increased the number of service veterans seeking

care in civilian communities. Professionals located in areas previously underrepresented by servicemembers and their families now have new opportunities to increase their practice to include this unique population. Since civilian providers will likely address the needs of the military population - both currently and into the near future-regional training should be a high priority.

The purpose of this article is to aid in expanding the provider's toolbox and enhance the care model to include cultural-specific awareness. It offers those providers less familiar with military customs and traditions ways to build their cultural competency and understanding of combat-related issues through several training resources. Appendix 1 provides a list of common military acronyms and terminology to facilitate familiarity with this culture's language diversity.

In addition, Appendix 2 contains links to some practical tools and military-sponsored websites for training on military specific issues. Please note this is not an exhaustive list, it is just some examples of how the Department of Defense fosters coordination between military and civilian resources. There are multiple military organizations collaborating with civilian-based services to enhance and advance the available care for military members and their families. Behavioral health and social support providers that get involved and make positive changes will not only be better prepared for the arrival and 
treatment of military members and their families-but will ultimately improve the care and support for the entire civilian community.

\section{References}

Abbe, A., Gulick, L. M. V., \& Herman, J. L. (2007). Cross-cultural competence in Army leaders: A conceptual and empirical foundation. Washington, DC: U.S. Army Research Institute.

Bride, B. E., \& Figley, C. R. (2009). Secondary trauma and military veteran caregivers. Smith College Studies in Social Work, 79(3), 314-329.

Buck, J. H. (1981). Professional ideals and military behavior. Air University Review, Mar-Apr. Retrieved from http://www.airpower.au.af.mil/airchronicles/aureview/1981/mar-apr/buck.htm

Chassman, J., \& Cave, C. (2011). Cultural, Ethnic and Racial Groups. Office of Mental Health. Retrieved from http://www.omh.state.ny.us/omhweb/savinglives/volume2/cultural groups.html

Corporation for National and Community Service (CNCS). (2010). Retrieved from http://www.serve.gov/

Cozza, S. J. (2011). Children of military service members: Raising national awareness of the family health consequences of combat deployment. Archives of Pediatrics and Adolescent Medicine. doi: 10.1001/archpediatrics.2011.117

Department of Defense. (2011). Base Realignment and Closure 2005. Retrieved from http://www.defense.gov/brac/

Department of Defense (DoD). (2010). Population Representation in the Military Services FY2010 Report. Retrieved from http://prhome.defense.gov/RFM/MPP/ACCESSION\%20POLICY/PopRep2010/

Defense Centers of Excellence (DCoE). (2009). Military Cultural Competence. Retrieved from http://www.essentiallearning.net/student/content/sections/Lectora/MilitaryCultureCo mpetence/index.html/

Figley, C. R. (Ed.). (1995). Compassion fatigue: Coping with secondary traumatic stress disorder in those who treat the traumatized. New York: Brunner/Mazel.

Franklin, E. (2009). The emerging needs of veterans: A call to action for the social work profession. Health \& Social Work, 34(3), 163-167.

Garcia, M. (2009). Combat to community: Needs and resources for post-September 11 veterans. Cultural competency: Iraq and Afghanistan veterans. Podcast retrieved from http://www.uctv.tv/search-details.aspx?showID=15597/

Hall, L. K. (2008). Counseling military families: What mental health professionals need to know. New York: Taylor and Francis Group. 
Institute of Medicine (IOM). (2010). Returning home from Iraq and Afghanistan: Preliminary assessment of readjustment needs of veterans, service members, and their families. Committee on the Initial Assessment of Readjustment Needs of Military Personnel, Veterans, and Their Families; Board on the Health of Selected Populations, 1-193. Retrieved from http://www.nap.edu/catalog/12812.html/

Kennedy, C. H., \& Moore, B. A. (2008). Evolution of clinical military psychology ethics. Military Psychology, 20, 1-6.

Lee, H. A., Gabriel, R., \& Bale, A. J. (2005). Clinical outcomes of Gulf Veterans' Medical Assessment Programme referrals to specialized centers for Gulf veterans with post-traumatic stress disorder. Military Medicine, 170(5), 400-405.

Luby, C. (2010). Behavioral Health and Social Support Resources-El Paso Region. University of Texas at El Paso, College of Health Sciences \& School of Nursing. Retrieved from http://chs.utep.edu/pdf/BehavioralHealthandSocialSupportResourcesElPasoRegionJu ne2010.pdf/

National Association of Social Workers. (2006). Indicators for the achievement of the NASW standards for cultural competence in social work practice. Retrieved from http://www.socialworkers.org/

Operation READY. (2010). The Army Family Readiness Group Leaders Handbook. Retrieved from http://www.au.af.mil/au/awc/awcgate/army/frg_hdbk.pdf/

Papadopoulos, I. (2008). The Papadopoulos, Tilki and Taylor Model for developing cultural competence. Intercultural Education of Nurses and medical staff in Europe [from Papadopoulos, I., Tilki, M., \& Taylor, G. (1998), Transcultural care: A guide for health care professionals. Wiltshire, UK: Quay Books]. Retrieved from http://www.ieneproject.eu/download/Outputs/intercultural\%20model.pdf

Rabb, D. (2010). Military cultural competency. Cultural competency: Iraq and Afghanistan veterans. Retrieved from http://www.cominghomeproject.net/node/152/

RAND National Defense Research Institute. (2007). Demographic Characteristics. Retrieved from http://www.rand.org/pubs/monographs/2007/RAND_MG599.pdf/

Reger, M. A., Etherage, J. R., Reger, G. M., \& Gahm, G. A. (2008). Civilian psychologists in an Army culture: The ethical challenge of cultural competence. Military Psychology, 20(1), 21-35.

Ruzek, J. I., Curran, E., Friedman, M. J., Gusman, F. D., Southwick, S. M., Swales, P., ... \& Whealin, J. (2004). Treatment of the Returning Iraq War Veteran. In: Iraq War Clinician Guide, NCPTSD Manual. Retrieved from http://ncptsd.va.gov/ncmain/ncdocs/manuals/iraq_clinician_guide_v2.pdf/

Substance Abuse Mental Health Services Administration (SAMHSA). (2006). Stigma in the Military: Strategies for Reducing Stigma Among Veterans and Active Duty Personnel. Training Teleconference. Retrieved from 
http://www.stopstigma.samhsa.gov/teleconferences/archive/training/teleconference03 3006.aspx/

Slone, L. B., \& Friedman, M. J. (2008). After the war zone: A practical guide for returning troops and their families. Philadelphia, PA: Da Capo Press.

U. S. Army Human Resource Command. (2011). US Army Physical Disability Agency. Retrieved from https://www.hrc.army.mil/site/Active/tagd/Pda/pdapage.htm/

U. S. Medicine Institute (USMI). (2005). The Changing Military Direct-Care System: Impact and Implications. Executive Summary-USMI Roundtable Discussion. Washington, D.C.

U. S. Army Warrior Transition Command (WTC). (2011). Families and Caregivers. Retrieved from http://wtc.army.mil/families/families.html/

\section{Author's note}

Address correspondence to Christi Duette Luby , Doctoral Candidate, College of Health Sciences/School of Nursing , University of Texas at El Paso, UTEP - Interdisciplinary Health Sciences Ph.D. Program, 500 W. University Ave., El Paso, TX 79968. E-mail: cdluby@miners.utep.edu 


\section{Appendix 1: Common Term/Acronym Definitions}

http://www.dtic.mil/doctrine/dod_dictionary

AAR After Action Report: After a mission, senior enlisted noncommissioned officers go through what happened and make a report to refer problems out to the appropriate resource providers.

Active Duty full-time job as part of a military force for a specified time period (enlistment)

ACU-Army Combat Uniform, BDU-Battle Dress Uniform, DCU-Desert Combat Uniform: military issued camouflage clothes used in various environments

AMC Army Medical Center

AOR Area of responsibility

AWOL Absent without Leave

Base Air Force or Navy Installation

Battlemind Resiliency training every soldier goes through

Battlerattle Body armor

BCT Brigade Combat Team: Army's basic deployable unit of maneuver

BOG Boots on the ground--personnel deployed under military command

BRASS Breathe, Relax, Aim, Slack, Squeeze- Marksmanship Training steps for shooting a gun

Camp Marine Corps Installation

CBERN Chemical, Biological, Explosive, Radiological and Nuclear hazards may be present

Citizen Soldier Reserve and National Guard service members called up to active-duty

CO Commanding Officer

Combat Ready Service member status when eligible for deployment/capable of performing duty

Commissioned officer derives authority “commission” by sovereign power, outranks enlisted personnel

CONUS Continental United States

COSC Combat/Operational Stress Control: Deployment related stress problems

COSR Combat Operational Stress Response: a normal response to an abnormal situation

DEMOB Demobilization: disassembling troops from combat-ready status; discharge of troops

Deployment Service member called to duty away from home base, not accompanied by family

Dwell Time The amount of time a soldier spends at home between deployments Down Range Deployed usually overseas, often in a combat zone

Enlisted personnel (rank or grade) Any rank below a commissioned or warrant officer; includes higher ranking enlisted Non-Commissioned Officers (NCO), and Petty Officers (Navy)

EOD Explosive Ordinance Disposal: safe and technical disposal of high explosive munitions 
FAC Family Assistance Center: National Guard family program assists families of all branches

Fisher House Free/low cost housing provided for family members of military patients FOB Forward Operating Base: secured area used in support of tactical operations.

Grade Refers to "pay grade” used for personnel and pay functions

GWOT Global War on Terrorism

HBCT Heavy Brigade Combat Team

HEMTT Heavy Expanded Mobility Tactical Truck re-supplies combat vehicles/weapons system

HMMWV High Mobility Multipurpose Wheeled Vehicle - pronounce "Humvee” military 4WD

Homefront Back at home, where their families are while they are deployed

IBCT Infantry Brigade Combat Team

IED Improvised Explosive Device

Inactive Duty after active duty, solider remains under contract, can be called back up for service

Inside the wire On the base (on the FOB)

ITOs Invitational Travel Orders: Provided by command to allow wounded warrior family visits

Kevlar Typically, the helmet made of the material Kevlar made for ballistic protection Leave Off Duty (usually vacation)

LSA Logistical Supply/Support Area: Military facility, depots, R \& R area, support to FOB

MEB Medical Evaluation Board (MEDBOARD) determines continued military service, referrals to PEB

MEDEVAC Medical Evacuation emergency evacuation of sick or wounded from combat area

MHC Medical Holding Company Facility care/support Active-duty patients not combat-ready

MOB Mobilization: assembling combat-ready troops and supplies for service deployment

MOS Military Occupational Specialty (career specialty) used by Army and USMC. USAF uses AFSC (Air Force Specialty Code); Navy uses NEC (Navy Enlistment Code). MRE Meal Ready to Eat

MST Military Sexual Trauma: sexual assault/harassment that occurs in military setting MTF Military Treatment Facility

NTC National Training Center

OCONUS Outside Continental United States

OIF/OEF Operation Iraqi Freedom (Iraq) / Operation Enduring Freedom (Afghanistan)

Oorah! Pronounced "Who-rah” what Marines say for "I get you/I hear you/I copy/I agree”

Hooyah! Pronounced "Who-yah” what Navy Seals say for "I get you/I hear you/I copy/I agree”

Hooah! Pronounced "Who-ah” what Army says for "I get you/I hear you/I copy/I agree” OPSEC Operational Security -being careful how use, say, and share critical information 
OPTEMPO Operations Tempo: pace of an operation or operations in terms of equipment usage

Outside the wire Going off the forward operating base (FOB) protected by razor wire PERSTEMPO Personnel tempo: time an individual spends away from home station. PCS Permanent Change of Station: move from one duty station to another (Relocating) PEB Physical Evaluation Board determines member's fitness for duty, disability, or medical separation

Post Army installation

PX- Post Exchange Army department store; Air Force "Base Exchange” (BX); "Navy Exchange” (NEX)

Rank status and authority of personnel in relation to other military members

Rate used by Navy and Coast Guard for sailors, means same thing as rank

Redeploy to move military forces from one combat zone to another, or to return to home base

Reserve members liable for active duty recall to augment active duty in war/national emergency

RPG Rocket Propelled Grenade: hand-held, shoulder-launched rocket

R \& R: Rest and Relaxation Time off for service member approx halfway through

deployment

Sandbox, sandpit Iraq

SBCT Stryker Brigade Combat Team

SICK CALL Time allotted to see Doctor or other healthcare provider.

TDY Temporary Duty

"Three Hots and a Cot": Service members in theater are provided three hot meals \& a bed

UMT Unit Ministry Team: chaplain (officer) and a chaplain assistant (enlisted soldier)

USA United States Army; branch of military, Personnel: "Soldier"

USAF United States Air Force; branch of military, Personnel: "Airman”

USCG United States Coast Guard; branch of military, Personnel "Sailor"

USMC United States Marine Corps; branch of military, Personnel: "Marine"

USN United States Navy; Personnel: "Sailor"

UXO Unexploded ordinance

VBED- Vehicle Borne Explosive Device

VBIED- Vehicle Borne Improvised Explosive Device

Veteran Status served in military, discharged/released with other than a dishonorable discharge

Warrant Officer officer who derives authority from a warrant, as opposed to a commission

XO Executive Officer assists Commanding Officer (CO); second in command in military unit 


\section{Appendix 2: Military Cultural Competence Resources and Fact Sheets}

1) Center for Deployment Psychology (2009) trains military and civilian behavioral health professionals to provide high quality care necessary to address deployment-related needs of military personnel and their families. http://www.deploymentpsych.org/

2) The Combat Injured Family: Guidelines for Care for Providers http://www.cstsonline.org/csts_items/RFR_combat_injured_family_guidelines_care_provider_she et.pdf

3) The Impact of Military Duty and Military Life on Individuals and Families: Resources and Intervention http://www.sagepub.com/booksProdTOC.nav?prodId=Book232979

4) "10 Things Military Teens Want You to Know" http://support.militaryfamily.org/site/DocServer/TOOLKIT_8.5x11_proof6.pdf?docID=15601\&JS ervSessionIdr002=nro0dds6

5) Understanding the Experience of Military Families and Their Returning War Fighters: Military Literature and Resource Review http://www.familyhomelessness.org/

6) The Combat Injured Family: Guidelines for Care http://www.cstsonline.org/csts_items/RFR_combat_injured_families_guidelines_care_patient_she et.pdf

7) Caring for America's Children: Military Youth in Time of War http://pedsinreview.aappublications.org/content/vol30/issue6/index.dtl

8) Military Officers Association of America http://www.moaa.org/usergroup/usergroup_fam/usergroup_fam_spouse/default.htm

9) Casualty Assistance Information: Meeting the Needs of Military Families and Children http://66.92.43.14/focus/CSTS_Casualty_Assistance_Information.pdf

10) Operations Security (OPSEC) Guide for Family and Friends http://www.armymedicine.army.mil/sfrc/OPSECTrifold.pdf

11) "REACH for Diversity": Respect individual differences, cultures, customs; Education of diversity adds to organization; Awareness of how people are similar, different, and unique; Collaboration with diverse providers build strong partnerships; and Honesty be honest with others, and ourselves its normal to fear people/ideas not understood. Learn to respect and appreciate differences, uniqueness. (Adapted from Dept of Veterans Affairs program) http://www1.va.gov/Diversity/page.cfm?pg=7

12) Civilian provider web resource for PTSD and TBI http://www.health.mil/Education_And_Training/Civilian_Provider_Education.aspx

13) inTransition (DCoE program) provides service members currently receiving mental health treatment with support as they transfer between health care systems or providers. www.health.mil/inTransition

14) Wellness resources for the military community—service members, veterans, families, and providers. www.afterdeployment.org 